\title{
The Role of the ADVICE Training Model in Improving Medical Physics Competency in North Sumatera
}

\author{
Ikhsan Bagatondi Nasution ${ }^{1, *}$ Efendi Napitupulu ${ }^{2}$ Harun Sitompul ${ }^{3}$ \\ ${ }^{1,2,3}$ Universitas Negeri Medan \\ "Corresponding author. Email: ikhsan.edutech@gmail.com.
}

\begin{abstract}
The prevalence of cancer in Indonesia is 1.8 per 1000 population. Radiotherapy is a fundamental part of effective treatment and management of cancer. Radiotherapy equipment can be used optimally by competent medical physicists, but in North Sumatra not all physicists have sufficient competence due to technical reasons leading to lack of access to training in their field, so it is necessary to provide special training for medical physicists with ADVICE model training. The paper will determine the effect of ADVICE training model on the competence of medical physicists in North Sumatra, by seek the differences in competency scores before and after training with ADVICE model. The competencies assessed included cognitive, affective, and psychomotor over treatment planning system (TPS)-material for seven medical physicists working in different hospitals in Medan City. This paper conducted the conclusion the mean cognitive score of respondents increased from 51.85 during the pretest to 90.28 during the posttest. The affective value of respondents as much as $85 \%$ has a value $>90$. The average psychomotor score is 87.5 to 96.8 . The ADVICE training model improves the competence of medical physicists in North Sumatra.
\end{abstract}

Keywords: medical physicist, competency, radiotherapy, ADVICE training model.

\section{INTRODUCTION}

Cancer is a complex disease, with patterns and trends in mortality varying widely from country to country. Changes in lifestyle and local exposure to certain factors are believed to be the triggers for cases. Cancer mortality is declining in most countries with high Human Development Index (HDI), this is due to the success of the fight against cancer in general through prevention, early detection and early intervention. However, for countries with low HDIs, insufficient access to affordable primary care, early detection and treatment remain obstacles to effective prevention and treatment, leading to poorer patient survival. Facilities for cancer surgery are available in $95 \%$ of high-income countries with a mortality rate of $45 \%$, but this figure is only about $25 \%$ in low-income countries, with a higher cancer mortality rate of $70 \%$ [1]

In Indonesia, the prevalence of cancer is 1.8 per 1000 population [2]. In addition to surgery and chemotherapy, radiotherapy is a fundamental part of effective cancer treatment and management. It is estimated that about half of cancer patients will benefit from radiotherapy for treatment. In high-income countries, although the available facilities for radiotherapy are not yet optimally utilized, there is therefore a global shortage of radiotherapy services. Especially in low-income countries, about $90 \%$ of the population does not have access to radiotherapy. The increasing cancer burden will increase the demand for radiotherapy that is already scarce worldwide [3].

Data from the International Atomic Energy Agency (IAEA) for 2012 estimate that there is currently a shortage of at least 5,000 radiotherapy devices in developing countries. This shortage suggests that nearly $70 \%$ of cancer patients in low-income countries are unable to benefit from curative radiation treatment for pain relief. There are relatively few radiotherapy facilities in developing countries and the condition is very poor and there is a lack of adequate staff. 
Radiotherapy equipment requires maximum efforts to use it optimally and competent human resources (HR) to operate it. Medical physicist is one of the defining human resources [4].

The results of conducted research [5] show that the needs of medical physicists in Indonesia are still insufficient, both in terms of number and competencies, as evidenced by competency certificates. Currently, only students who participate in education or training and education organized by AIPFMI have competency certificates. It becomes a problem if the Medical Physicist already has a Certificate of Registration, but not yet a Certificate of Competence, as this is not in line with the Medical Physicist's professional standards.

The main focus of the Ministry of Health in providing training for the Functional Position of Medical Physicists is for Civil Servants [6], so additional training is needed for Medical Physicists who are not civil servants. Using the instructional design ADVICE, a training model was developed. Training with the ADVICE model is a series of training activities consisting of Analysis, Design, Verification, Implementation, Control and Evaluation. This training is in the form of an educational design application as a result of development that is equipped with an output in the form of a training video, so that participants will easily understand the training material due to the nature of this training which is easy and flexible. This model can be used as a guide for medical physicists when conducting medical physics training so that all competencies required in the competency standard can be easily mastered by training participants.

Most of the medical physicists in North Sumatra are not civil servants and have never received training due to various constraints such as limited time, limited facilities and high cost. For this reason, the authors are interested in providing training based on the ADVICE model to enhance the competence of medical physicists in North Sumatra.

\section{INTRODUCTION TO ADVICE TRAINING MODEL}

This ADVICE training model can be explained briefly in the form of a scheme as follows

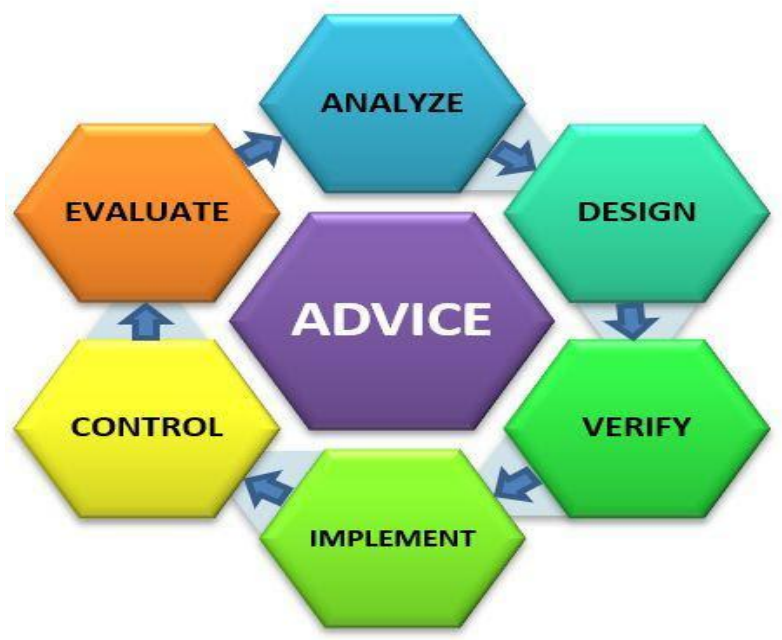

Figure 1. ADVICE Training Model.

\subsection{Analyze Stage}

The purpose of the Analysis phase is to identify possible causes of performance gaps. In the context of the ADVICE training model, the analysis phase as the first step is based on the results of the literature analysis and field analysis. Analysis of the literature on the training model that exists among Radiotherapy Medical Physicists in the North Sumatra region has not shown a model that has the characteristics of a Medical Physicist's work. Currently, the training model for Medical Physicists in North Sumatra is still limited to the direct instruction model, which is centered on the instructor.

\subsection{Design Stage}

The purpose of the design for the Participant must be in accordance with its classification. The level of competence to be achieved. Instructional media design in accordance with existing conditions. The training designer in this step thinks about how design instruction can be truly effective in a way that facilitates learning from people and interacting with the material created and delivered. In addition, instructional designers develop and focus on assessing designs for their subjects, selecting course forms, and creating their own instructional strategies.

\subsection{Verify Stage}

The purpose of verify stage ensures that the things done in the analysis and design are really appropriate to be continued at the implementation stage. Verification carried out is verification of training participants, verification of instructors, verification of training facilities. If the verification does not match the existing reality, it is necessary to redesign. This verification is an activity that must pass the test, because this stage determines whether something that is to be clarified or 
verified has indeed met all the requirements needed before it is implemented.

\subsection{Implement Stage}

The purpose of implement stage ensures the results of product designs that have passed verification need to be tested in real terms in the field to obtain an overview of the level of effectiveness, attractiveness, and learning efficiency. The implementation of this ADVICE model implementation phase in training for participants is by asking various questions related to the things mentioned above (through a questionnaire), while for instructors a checklist is given regarding these questions.

\subsection{Control Stage}

The control phase is the next step in the design of ADVICE training after implementation, it is necessary to ensure that everything that has been designed and passed the verification can be implemented correctly and completely. This stage also ensures that implementation stays on track that has been previously designed. This stage ensures that all training materials have been delivered correctly and considering that some training for Radiotherapy Medical Physicists must be mastered 100\% without errors [7] before being applied to patients who need it.

\subsection{Evaluation Stage}

In relation to the ADVICE training model, the last stage is to conduct an overall evaluation of the steps taken. If the evaluation results show good results, then a product is created that becomes a reference for making further products or becomes relevant learning material at this time. The development of the ADVICE model states that training produces products that require social interaction and will develop understanding, and increase experience which then becomes an expert in that field.

\section{ANALYSIS}

The research design used in this paper is descriptive analysys, to see the differences in competency scores before and after training with the ADVICE model. The competencies assessed include cognitive, affective, and psychomotor over treatment planning system (TPS)material. This study was conducted in April 2021 in hospitals in Medan City and Deli Serdang Regency, including: Haji Adam Malik Hospital, Murni Teguh Memorial Hospital, Vina Estetica Hospital, the training lasts for one week and is conducted online using Zoom application. The respondents in this study were seven medical physicists working in the Radiotherapy Department. The training material provided is about TPS. The data was analyzed descriptively by looking at the number of values obtained. The data are then compared between the values before and after the training to find out the differences in the scores of doing Treatment Planning System before and after the training.

\subsection{Comparison of cognitive value.}

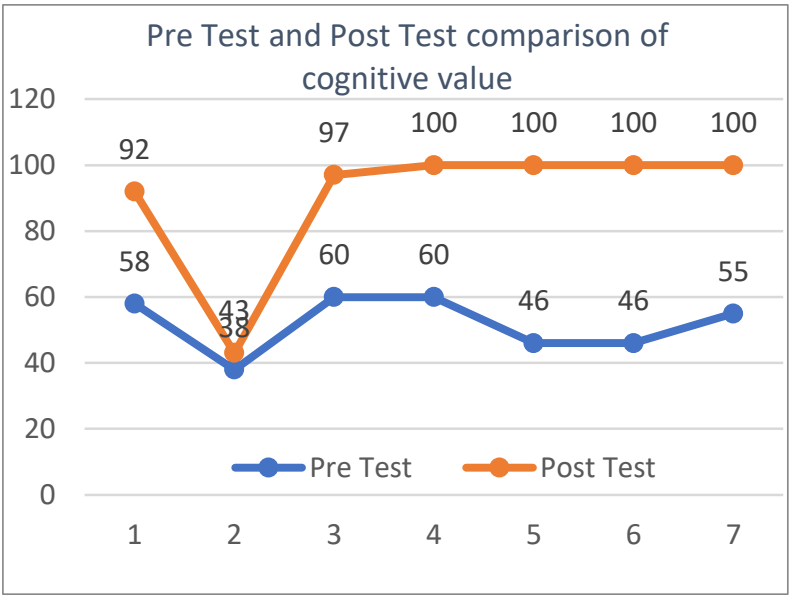

Figure 2. Comparison of cognitive value

Figure 2. shows the value of differences in cognitive aspects in the pretest and posttest. The comparison of pretest and posttest results on the training participants can be seen by the average value obtained. The percentage of comparison of learning outcomes seen from the cognitive aspect, the mean pre-test score was 51.85, while the mean post-test score was 90.28 . The percentage comparison of cognitive scores between pre-test and post-test was 38.4 points. Overall, it shows an increase in value, even though the range of values is varied (5-54 points).

\subsection{Comparison of affective value.}

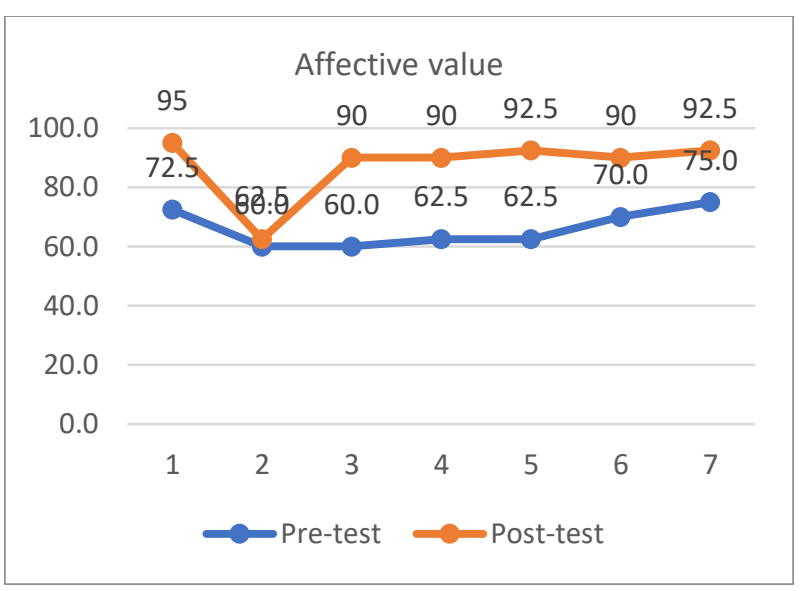

Figure 3. Comparison of affective value

The affective value of the training participants who used the ADVICE model showed very good scores, where $85.7 \%$ of the training participants scored above 90 , only one participant had a lower score. 


\subsection{Comparison of psycomotor value.}

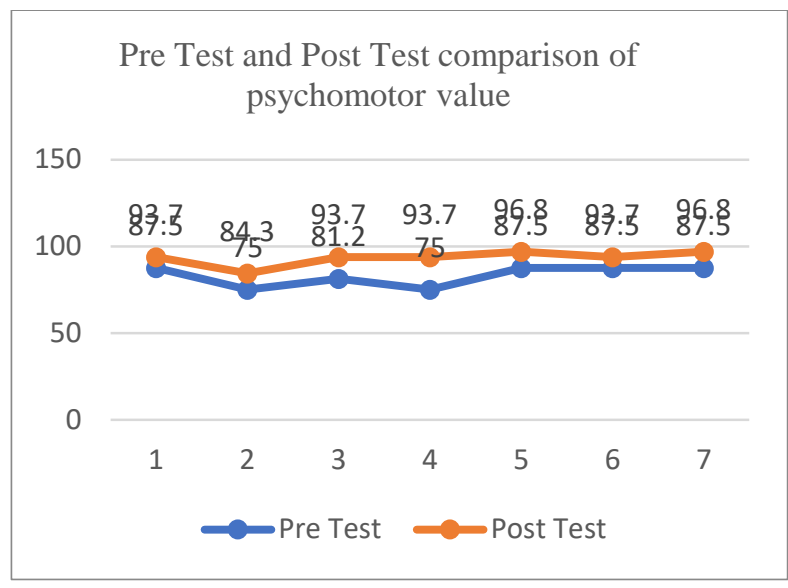

Figure 4. Comparison of pyscomotor value

Comparing the learning outcomes of training participants based on psychomotor aspects, the mean pretest score was 87.5 and the mean posttest score was 96.8. The difference in psychomotor scores between the pretest and posttest was 9.3 points. In general, there was an increase in the intermediate value before an intervention, the variation in values ranged from 6.2 to 18.7 points.

\section{RECOMMENDATION FOR ADVICE TRAINING MODEL.}

Firstly, ADVICE training model recommended for training that performs verification steps prior to implementation and control steps to oversee implementation.

Secondly, the role of this ADVICE training model has succeeded in providing increased competence for Medical Physicists, it is necessary to continue with other field training in the work of medical physicists with more participants in order to provide more significant results.

Thirdly, further research is needed on the use of the ADVICE training model outside the scope of training for medical physicists.

\section{CONCLUSION}

In this paper, it can be seen that based on the assessment of the cognitive aspects, it appears that the mean value increased from 51.85 during the pretest to 90.28 during the posttest. The comparison of cognitive scores between the pretest and posttest was 38.4 points. From the affective aspect, it can be seen that $85 \%$ of the respondents have a value $>90$, but one person has a value of 62.5. This needs further investigation. Similarly with the psychomotor scores, the average pretest score was 87.5 to 96.8 at the time of posttest. On deeper examination, the pretest score on psychomotor was 87.5: 51.58 on the cognitive pretest score.
The ADVICE training model improves the competence of medical physicists in North Sumatra. Overall, the competence of the trainees increased after attending ADVICE model training.

\section{ACKNOWLEDGMENTS}

First and foremost, I would like to show my deepest gratitude to my professors in Universitas Negeri Medan, who have provided me with valuable guidance in every stage of the writing of this paper. Further, I would like to thank all my friends for their encouragement and support. Without all their enlightening instruction and impressive kindness, I could not have completed my paper.

\section{REFERENCES}

[1] WHO, World cancer report 2020. 2020.

[2] Riskesdas 2018, "Riskesdas 2018," Lap. Nas. RIskesdas 2018, 2018.

[3] R. Atun et al., "Expanding global access to radiotherapy," The Lancet Oncology. 2015, doi: 10.1016/S1470-2045(15)00222-3.

[4] M. Samiei, "Challenges of making radiotherapy accessible in developing countries," Cancer Control, 2013.

[5] S. A. Pawiro, L. E. Lubis, A. N. Oktavianto, and ..., "Professional Training Scheme to Answer National Demand Medical Physicists in Indonesia," Med. ..., 2020.

[6] Kemenkes, "Standar Kurikulum dan Modul Pelatihan Kompetensi FM," 2013, [Online]. Available:

http://siakpel.bppsdmk.kemkes.go.id:8102/akred itasi_kurikulum/kurikulum_1910140126494daa b1f198ec8e1fa182053d56567479.pdf.

[7] WHO, Radiotherapy Risk Profile. Geneva: WHO Press, 2008. 